\title{
Correlates of out-of-pocket and catastrophic health expenditures in Tanzania: results from a national household survey
}

\author{
Ethel Mary Brinda*, Rodriguez Antonio Andrés and Ulrika Enemark
}

\begin{abstract}
Background: Inequality in health services access and utilization are influenced by out-of-pocket health expenditures in many low and middle-income countries (LMICs). Various antecedents such as social factors, poor health and economic factors are proposed to direct the choice of health care service use and incurring out-of-pocket payments. We investigated the association of these factors with out-of-pocket health expenditures among the adult and older population in the United Republic of Tanzania. We also investigated the prevalence and associated determinants contributing to household catastrophic health expenditures.

Methods: We accessed the data of a multistage stratified random sample of 7279 adult participants, aged between 18 and 59 years, as well as 1018 participants aged above 60 years, from the first round of the Tanzania National Panel survey. We employed multiple generalized linear and logistic regression models to evaluate the correlates of out-of-pocket as well as catastrophic health expenditures, accounting for the complex sample design effects.

Results: Increasing age, female gender, obesity and functional disability increased the adults' out-of-pocket health expenditures significantly, while functional disability and visits to traditional healers increased the out-of-pocket health expenditures in older participants. Adult participants, who lacked formal education or worked as manual laborers earned significantly less $(p<0.001)$ and spent less on health $(p<0.001)$, despite having higher levels of disability. Large household size, household head's occupation as a manual laborer, household member with chronic illness, domestic violence against women and traditional healer's visits were significantly associated with high catastrophic health expenditures.

Conclusion: We observed that the prevalence of inequalities in socioeconomic factors played a significant role in determining the nature of both out-of-pocket and catastrophic health expenditures. We propose that investment in social welfare programs and strengthening the social security mechanisms could reduce the financial burden in United Republic of Tanzania.
\end{abstract}

Keywords: Tanzania, Catastrophic expenditures, Out-of-pocket payments, Traditional healers

\section{Background}

Low and middle income countries (LMICs) support $84 \%$ of the global population, comprise $90 \%$ of the global disease burden and yet, account for only $12 \%$ of global resources spent on health [1]. Public expenditures on health, as a share of their Gross Domestic Product (GDP) are significantly less in LMICs [2,3]. Most of the health expenditures are paid directly as out-of-pocket (OOP) payments

\footnotetext{
* Correspondence: ebam@soci.au.dk

Department of Public Health, Section for Health Services Research and Health Promotion, Aarhus University, Aarhus C 8000, Denmark
}

[4]. LMICs also experience overlapping health transition [5] with the additional burden of both infectious and chronic diseases.

The vast majority of African countries rely on direct OOP health expenditures and experiences a high burden of catastrophic health expenditures [6-8]. Tanzania with its growing ageing population, supports a current older population (60 years and above) of 1.5 million, which is projected to increase to 3 million by 2025 [9]. Tanzania spends a low share of GDP $(7.2 \%)$ on health, with a meagre public expenditure of $39 \%$ of the total health 
costs [10]. The OOP health expenditures account for $52 \%$ of total health spending, while various public and private pre-payment schemes contribute the remaining expenditures [11]. User fees at public health facilities were introduced in Tanzania in the 1990s with the intention of mobilizing resources and providing sustainable healthcare [12]. However, ineffective exemption systems, ancillary health care costs of the health seekers through transportation, food and accommodation escalates the high OOP health expenditures [13]. Health care seeking through private healthcare and faith-based health facilities or traditional healers contributes to most of the health service utilization [14]. These providers charge user fees, have some waiver system and do not provide exemptions [12].

Affordability [15] and accessibility [4] determine health service utilization in many LMICs. The use of essential health services are reported to be avoided by poor people with the increasing demand for OOP health expenditures $[16,17]$. Andersons' behavioral model aids the theoretical understanding of the nature of health service utilization and subsequent OOP health expenditures in LMICs $[3,18]$. High OOP health expenditures have a serious impact on vulnerable people who subsequently experience debt, income loss and catastrophic health expenditures $[7,19]$. Health expenditures are regarded catastrophic, when they exceed $40 \%$ of household's effective income remaining after subsistence needs [20].

Knowledge about the determinants of OOP expenditure on health is vital from a health policy perspective, to inform the design of interventions or system changes that ensure accessible and financially protective health services to vulnerable people. The studies on determinants of OOP health expenditure in various LMICs are primarily focused on adult populations. The research findings cannot necessarily be extrapolated to older people who differ in disease patterns [21], health-seeking behaviors [22] and access to resources in LMICs [10]. Moreover, the relative absence of social welfare policies and inequitable access to health services require the specific assessment of OOP health expenditures prevalent in LMICs $[4,23]$. Hence, we aim to investigate the determinants influencing OOP health expenditures among the adult as well as the older population aged above 60 years in Tanzania. We also intend to explore the determinants of catastrophic health expenditures based on Tanzanian households' non-food expenditures.

\section{Methods}

\section{The Tanzania National Panel survey}

We employed a cross-sectional study design. This study uses secondary data from the first round of Tanzania National Panel Survey (TZNPS), implemented by National
Bureau of Statistics of United Republic of Tanzania [24]. The first wave of the survey was conducted between October 2008 and October 2009. TZNPS employed multistage, stratified, random sampling to generate nationally representative samples. The first stage of sampling units comprised 410 clusters of enumeration areas in urban and rural areas. The second stage involved 3265 households. All members of the selected households were invited and those who provided verbal informed consent, were included in the study. The final sample included 8297 participants, of which 7279 were aged between 18 and 59 years and 1018 participants were above 60 years. The details of the participants' sampling information are available elsewhere [24]. To obtain individual and household level data, trained field staffs conducted person-toperson interviews employing structured questionnaires and recorded anthropometric measures [24]. At the individual level, the data included socioeconomic characteristics, self-reported disabilities, health service visits and OOP health expenditures by type of health facilities. Data on household characteristics, availability of durable assets, household's total health expenditures and basic facilities like access to safe drinking water and toilet facilities for the past 4 weeks were recorded. The OOP health expenditures included the utilization of private outpatient clinics, preventive health services, over-the counter medications and use of traditional healer services.

\section{Variable specification}

Based on Anderson's model, the factors determining the health care demand were categorized into predisposing, enabling and need factors. We included age, gender, marital and occupation status variables as predisposing factors; education, asset index as proxy measures for wealth were considered as enabling factors to OOP health expenditures. The asset index was estimated using eighteen variables, which provided information on housing characteristics, type of water supply, sanitation in the household, and ownership of the household's durable assets. Obesity, presence of visual defects, hearing defects, limb defects, self-reported functional disabilities and psychological morbidity were included as need variables.

\section{Statistical analyses}

We initially analyzed the study variables using descriptive statistics. We used the statistical technique, Principal Component Analysis (PCA) to construct the asset index [25]. We performed Kaiser-Meyer-Olkin (KMO) measure of sampling adequacy. The obtained value of 0.80 was liable for conducting PCA. Scoring factors were derived from the first principal component, which was a linear index of variables with common information, and this score was used to construct the household's asset index. We used Mann-Whitney U and Chi-square test to assess 
the bivariate associations between the study variables. Our outcome variable OOP health expenditure was typically non-parametric and positively skewed with influential outliers. Traditional ordinary least square regressions with log-transformation and retransformations are too inconsistent to handle skewness and provide inferences in natural units of mean expenditures [26]. Generalized linear regression models (GLM) are flexible to model skewed expenditure data and avoid the issue of outcome transformation [27]. Survey GLM with gamma distribution and log link function $[28,29]$, was employed to assess various determinants of OOP health expenditures and account for the complex survey design.

To analyse the determinants of catastrophic health expenditure, we used non-food expenditures of the household as a close measure for the household's capacity to pay. We estimated the share of OOP health expenditure in the household's non-food expenditure $\left(E_{j}\right)$ to define catastrophic health expenditure:

$$
\mathrm{E}_{j}=\mathrm{HE}_{j} / \mathrm{NFE}_{j} * 100
$$

Where, $\mathrm{HE}_{j}$ is the household's average monthly OOP health expenditure; $\mathrm{NFE}_{j}$ denotes the household's average monthly non-food expenditure. We dichotomized and coded the outcome as ' 1 ', when $\mathrm{E}_{j}$ exceeded the threshold of 40\% [7], ' 0 ' if otherwise. We employed survey logit model to assess the determinants of catastrophic health expenditure in households. We performed all analyzes using statistical software STATA 12.1.

\section{Results}

We present the socio-demographic and health profiles of the study participants in Table 1. In the following, the study participants aged between 18-59 years are referred to as adult participants and those aged 60 years and above are termed older participants.

\section{Participant characteristics}

A total of 7279 adults and 1018 older participants were included in the present study. Majority of the study participants were women. Most of the adult participants had primary education (86\%), while only $14 \%$ had more than primary education. Among the older participants, the majority were women, lacked formal education and had past occupation as manual laborers. Only 35\% of households had safe drinking water access, while 92\% households had access to toilet facilities. The average family size of the households was 5.1 (SD 2.8).

Nature of resources and needs among study participants The self-reported monthly income differed significantly between the adults and older participants (Mann- Whitney
Table 1 Socio-demographic and health profiles of the participants

\begin{tabular}{|c|c|c|}
\hline \multirow[t]{2}{*}{ Variables } & \multirow{2}{*}{$\begin{array}{l}\text { Adult population } \\
(\mathrm{n}=7279) \\
\text { Percentage/ } \\
\text { Mean (SD) }\end{array}$} & \multirow{2}{*}{$\begin{array}{l}\text { Older population } \\
(\mathrm{n}=1018) \\
\text { Percentage/ } \\
\text { Mean (SD) }\end{array}$} \\
\hline & & \\
\hline Age in years & $37.7(16.5)$ & $70.5(8.1)$ \\
\hline \multicolumn{3}{|l|}{ Gender: } \\
\hline Male & 46.5 & 46.9 \\
\hline Female & 53.5 & 53.0 \\
\hline \multicolumn{3}{|l|}{ Marital status: } \\
\hline Single/Married & 86.0 & 58.9 \\
\hline Widowed/separated & 14.0 & 41.1 \\
\hline \multicolumn{3}{|l|}{ Education: } \\
\hline No formal education & 24.3 & 60.3 \\
\hline Primary education & 61.3 & 34.3 \\
\hline Secondary education & 12.8 & 4.2 \\
\hline Higher secondary education & 0.7 & 0.1 \\
\hline Graduate & 0.9 & 1.0 \\
\hline \multicolumn{3}{|l|}{ Occupation status: } \\
\hline Manual laborers & 53.5 & 67.3 \\
\hline Others & 46.5 & 32.7 \\
\hline \multicolumn{3}{|l|}{ Lack of access to basic facilities: } \\
\hline $\begin{array}{l}\text { No access to safe drinking } \\
\text { water }\end{array}$ & 77.2 & 80.6 \\
\hline No access to toilet facilities & 9.6 & 6.9 \\
\hline \multicolumn{3}{|l|}{ Presence of disabilities: } \\
\hline Physical disabilities $^{a}$ & 4.3 & 12.6 \\
\hline Psychiatric disorders & 0.4 & 0.4 \\
\hline Functional disabilities & 4.9 & 25.7 \\
\hline \multicolumn{3}{|l|}{ Body Mass Index } \\
\hline Men & $22.0(5.4)$ & $21.7(4.2)$ \\
\hline Women & $23.2(4.9)$ & $22.3(5.2)$ \\
\hline $\begin{array}{l}\text { OOP health expenditures } \\
\text { (in US dollars) }\end{array}$ & $2.2(9.5)$ & $0.7(6.3)$ \\
\hline $\begin{array}{l}\text { Self-reported monthly income } \\
\text { (in US dollars) }\end{array}$ & $92.3(260.3)$ & $19.1(178.2)$ \\
\hline
\end{tabular}

${ }^{a}$ Physical disablity includes presence of visual impairment, hearing or limb defects; ${ }^{b}$ Body Mass Index in $\mathrm{Kg} / \mathrm{m}^{2}$.

$\mathrm{U}=3442425 ; \mathrm{p}<0.001)$. Adult women $(\mathrm{U}=5559127.0$; $\mathrm{p}<0.001)$ and those who worked as manual laborers $(\mathrm{U}=5328429.5 ; \mathrm{p}<0.001)$ had a significantly lower income. Older women had a significant lower income compared to older men $(\mathrm{U}=115054.0 ; \mathrm{p}<0.001)$. Adult women $\left(\chi^{2}=6.3 ; \mathrm{p}<0.001\right)$ and adult participants $\left(\chi^{2}=\right.$ 5.4; $\mathrm{p}<0.001)$ who lacked formal education reported higher disability. However, older women did not report higher disabilities $\left(\chi^{2}=2.8 ; \mathrm{p}=0.09\right)$. 


\section{Nature of health service utilization and OOP health expenditure}

About 1030 (14.2\%) of the adult participants had visited medical health services and 117 participants (1.6\%) had visited traditional healers within the past month. Older participants, who visited medical health services, were 190 (18.7\%). The adult participants utilized traditional healers or faith-based services significantly more than the older participants $\left(\chi^{2}=5.7 ; \mathrm{p}=0.01\right)$. However, private healthcare utilization did not significantly differ among the adults and older participants $\left(\chi^{2}=3.6\right.$; $\mathrm{p}=0.06)$. The mean OOP health expenditures among the adult participants, over the past month was 2.2 (SD 9.5) US\$, while the older participants' OOP health expenditure was 0.7 (SD 6.3) US\$. Total OOP expenditures were spent mostly on health professional fees 0.8 (SD 7.5) US\$, followed by over -the-counter medications 0.2 (SD 1.1) US\$ and hospital admissions 0.1 (SD 3.6) US\$.

\section{Correlates of OOP health expenditure among adult participants}

We present the bivariate and multivariate analyses for the correlates of adult OOP health expenditures in Table 2. Factors such as female gender, occupation as unskilled manual laborer, hearing defects and functional disability were significantly associated with higher adult OOP health expenditures. Traditional healer visits increased the OOP health expenditures among the adult participants. The higher OOP health expenditure among women could be attributed to expenditure on their reproductive health, because women aged above 45 years, had significantly less OOP health expenditures $(\beta=-0.37$; 95\% CI $-0.68,-0.04 ; \mathrm{p}=0.03)$, than men.

\section{Correlates of OOP health expenditure among older participants}

We present the bivariate and multivariate analyses for the factors associated with OOP health expenditures among the older participants in Table 3. Presence of visual impairment, Functional disability and traditional healthcare visits significantly increased the OOP health expenditure, after adjusting for potential confounders. Older participants with occupations as unskilled manual laborer spent significantly less out-of their pockets, despite a higher prevalence of disability. Among the older participants aged above 65 years $(n=744)$, unskilled manual laborers $(\beta=-0.71 ; 95 \% \mathrm{CI}-1.30,-0.12 ; \mathrm{p}=0.01)$ and those who lacked formal education $(\beta=-0.62 ; 95 \%$ CI $-1.21,-0.02$; $\mathrm{p}=0.04$ ) had lower OOP health expenditures. While, factors such as functional disability $(\beta=+0.89 ; 95 \% \mathrm{CI}+0.32,+1.46 ; \mathrm{p}=0.02)$, and visits to traditional healers $(\beta=+1.40 ; 95 \% \mathrm{CI}+0.41,+2.39$; $\mathrm{p}=0.006)$, increased their OOP health expenditures.

\section{Correlates of Catastrophic health expenditure in households}

The proportion of households that experienced catastrophic health expenditure was $18 \%$. We present the bivariate and multivariate analyses for the correlates of the households' catastrophic health expenditure in Table 4. During the multivariate analysis, factors such as household members with chronic illnesses, household head's occupation as a manual laborer, healthcare visits to a

Table 2 Factors associated with out-of-pocket health expenditure among adult participants (18yrs-59yrs) $(n=7279)$

\begin{tabular}{|c|c|c|c|c|}
\hline \multirow[t]{2}{*}{ Explanatory variables } & \multicolumn{2}{|c|}{ Bivariate statistics $^{a}$} & \multicolumn{2}{|c|}{ Multivariate statistics ${ }^{\mathbf{b}}$} \\
\hline & $\beta(95 \% \mathrm{Cl})$ & p value & $\beta(95 \% \mathrm{Cl})$ & $p$ value \\
\hline Age in years & $+0.02(+0.01 ;+0.04)$ & $<0.001$ & $+0.03(+0.02 ;+0.05)$ & $<0.001$ \\
\hline Female gender & $+0.42(+0.15 ;+0.68)$ & 0.002 & $+0.60(+0.34 ;+0.86)$ & $<0.001$ \\
\hline Lack of formal education & $-0.46(-0.80 ;-0.12)$ & 0.007 & $-0.33(-0.72 ;+0.06$ & 0.10 \\
\hline Widowhood & $+0.14(-0.29 ;+0.58)$ & 0.51 & $-0.29(-0.69 ;+0.09)$ & 0.13 \\
\hline Working as manual laborer & $-0.64(-0.91 ;-0.37)$ & $<0.001$ & $-0.62(-0.86 ;-0.39)$ & $<0.001$ \\
\hline Asset Index ${ }^{c}$ & $+0.03(-0.02 ;+0.07)$ & 0.26 & $+0.02(-0.02 ;+0.06)$ & 0.27 \\
\hline BMI more than $30\left(\mathrm{~kg} / \mathrm{m}^{2}\right)$ & $+0.99(+0.42 ;+1.55)$ & $<0.001$ & $+0.55(-0.08 ;+1.18)$ & 0.09 \\
\hline Presence of blindness/visual defect & $+0.01(-0.51 ;+0.53)$ & 0.96 & $-0.12(-0.74 ;+0.51)$ & 0.71 \\
\hline Presence of hearing defect & $+1.25(-0.20 ;+2.69)$ & 0.09 & $+1.96(+0.24 ;+3.68)$ & 0.02 \\
\hline Presence of limb defect & $+0.93(+0.36 ;+1.50)$ & $<0.001$ & $+0.51(-0.37 ;+1.39)$ & 0.25 \\
\hline Presence of psychiatric morbidity & $-0.62(-1.72 ;+0.48)$ & 0.27 & $+0.41(-1.18,+1.98)$ & 0.61 \\
\hline Presence of functional disability & $+1.77(+1.28 ;+2.25)$ & $<0.001$ & $+1.08(+0.56 ;+1.61)$ & $<0.001$ \\
\hline Traditional healer visits & $+1.66(+1.16 ;+2.16)$ & $<0.001$ & $+1.47(+1.23 ;+1.81)$ & $<0.001$ \\
\hline
\end{tabular}

${ }^{a}$ Survey generalized linear regression models with log link function using out-of-pocket health expenditure (in Tanzanian Schilling) as the dependent variable for adult participants aged between 18 and 59 years; ${ }^{b}$ Adjusted for all bivariate significant variables with out-of-pocket health expenditure (in Tanzanian Schilling) as the dependent variable; 'Asset Index constructed using Principal Component Analysis. BMI = Body Mass Index. 
Table 3 Factors associated with out-of-pocket health expenditure among older participants $(>60 \mathrm{yrs})(\mathrm{n}=1018)$

\begin{tabular}{|c|c|c|c|c|}
\hline \multirow[t]{2}{*}{ Explanatory variables } & \multicolumn{2}{|c|}{ Bivariate statistics $^{\mathrm{a}}$} & \multicolumn{2}{|c|}{ Multivariate statistics $^{b}$} \\
\hline & $\beta(95 \% \mathrm{Cl})$ & $p$ value & $\beta(95 \% \mathrm{Cl})$ & $\mathrm{p}$ value \\
\hline Age in years & $+0.01(-0.02 ;+0.04)$ & 0.64 & $-0.01(-0.04 ;+0.02)$ & 0.42 \\
\hline Female gender & $-0.35(-0.90 ;+0.19)$ & 0.20 & $-0.37(-0.89,+0.16)$ & 0.16 \\
\hline Lack of formal education & $-0.69(-1.23 ;-0.16)$ & 0.01 & $-0.48(-0.96,+0.01)$ & 0.05 \\
\hline Widowhood & $-0.13(-0.68 ;+0.42)$ & 0.63 & $-0.26(-0.73 ;+0.22)$ & 0.28 \\
\hline Worked as manual laborer in the past & $-0.73(-1.31 ;-0.15)$ & 0.01 & $-0.29(-0.90 ;+0.30)$ & 0.33 \\
\hline Asset Index ${ }^{c}$ & $+0.03(-0.04 ;+0.09)$ & 0.39 & $+0.06(-0.01 ;+0.12)$ & 0.08 \\
\hline BMI more than $30\left(\mathrm{~kg} / \mathrm{m}^{2}\right)$ & $+0.87(+0.26 ;+1.49)$ & 0.005 & $+0.62(-0.04 ;+1.28)$ & 0.06 \\
\hline Presence of blindness/visual defect & $+0.85(+0.22 ;+1.49)$ & 0.009 & $+1.03(+0.29 ;+1.77)$ & 0.01 \\
\hline Presence of hearing defect & $-0.61(-1.64 ;+0.43)$ & 0.25 & $-0.24(-1.35 ;+0.86)$ & 0.66 \\
\hline Presence of limb defect & $+0.11(-0.81 ;+1.04)$ & 0.81 & $-0.14(-1.04 ;+0.75)$ & 0.75 \\
\hline Presence of psychiatric morbidity & $-1.16(-2.60 ;+0.27)$ & 0.11 & $-0.98(-2.56 ;+0.60)$ & 0.22 \\
\hline Presence of functional disability & $+1.05(+0.53 ;+1.57)$ & $<0.001$ & $+0.70(+0.14 ;+1.26)$ & 0.01 \\
\hline Traditional healer visits & $+1.67(+0.69 ;+2.65)$ & $<0.001$ & $+1.43(+0.66 ;+2.20)$ & $<0.001$ \\
\hline
\end{tabular}

aSurvey generalized linear regression models with log link function using out-of-pocket health expenditure (in Tanzanian Schilling) as the dependent variable for

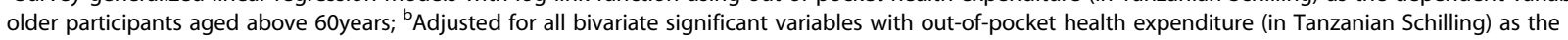
dependent variable ; ${ }^{\mathrm{C}}$ Asset Index constructed using Principal Component Analysis. BMI= Body Mass Index.

traditional healer, a household size of more than five and domestic violence against women significantly increased the likelihood of experiencing catastrophic health expenditure, after adjusting for all bivariate significant variables. Wealthy households were spared catastrophic health expenditure.

\section{Discussion}

Our study evaluated the nature and correlates of OOP health expenditures among adult and older participants in the United Republic of Tanzania. Its strengths include a relatively larger sample size, representative sampling and studying a combined model of social as well as health correlates. However, self-reported healthcare variables risk the possibility of recall and response bias. Cross-sectional nature of this study prevents establishing any causal associations. Unavailability of data on disease variables to explain the need for OOP health expenditures can be a potential limitation of this study.

\section{Correlates of OOP health expenditure among adults and older people}

Women of reproductive age had a significantly higher OOP expenditure than the older women in our study. This is in line with a Tanzanian study, which reported

Table 4 Factors associated with catastrophic health expenditure in the households of Tanzania $(n=3265)$

\begin{tabular}{|c|c|c|c|c|}
\hline \multirow[t]{2}{*}{ Explanatory variables } & \multicolumn{2}{|c|}{ Bivariate statistics $^{a}$} & \multicolumn{2}{|c|}{ Multivariate statistics $^{\mathbf{b}}$} \\
\hline & OR $(95 \% \mathrm{Cl})$ & $\mathrm{p}$ value & OR $(95 \% \mathrm{Cl})$ & $p$ value \\
\hline Age(in years) of the household head & $1.00(0.99,1.01)$ & 0.06 & $1.00(0.99,1.01)$ & 0.14 \\
\hline Women being household head & $1.04(0.84,1.27)$ & 0.73 & $1.05(0.85,1.30)$ & 0.61 \\
\hline Household head without formal education & $1.26(0.97,1.64)$ & 0.08 & $0.80(0.59,1.08)$ & 0.15 \\
\hline Household head being manual laborer & $1.75(1.28,2.39)$ & $<0.001$ & $1.54(1.11,2.12)$ & 0.01 \\
\hline Household size more than 5 & $2.15(1.77,2.61)$ & $<0.001$ & $1.68(1.37,2.07)$ & $<0.001$ \\
\hline Asset Index ${ }^{c}$ & $0.83(0.67,1.03)$ & 0.09 & $0.78(0.62,0.98)$ & 0.03 \\
\hline Household member with functional disability & $1.61(1.29,2.02)$ & 0.04 & $1.19(0.93,1.51)$ & 0.15 \\
\hline Violence against women & $1.80(1.36,2.39)$ & $<0.001$ & $1.41(1.05,1.91)$ & 0.02 \\
\hline Household member affected with chronic disease & $2.01(1.50,2.68)$ & $<0.001$ & $1.92(1.43,2.58)$ & $<0.001$ \\
\hline Traditional healer visits of the household & $5.17(3.01,8.86)$ & $<0.001$ & $3.38(1.96,5.81)$ & $<0.001$ \\
\hline
\end{tabular}

${ }^{a}$ Survey logistic regression models with catastrophic health expenditure as the dependent variable; ${ }^{b}$ Adjusted for bivariate significant covariates with, catastrophic health expenditure as the dependent variable; ${ }^{\mathrm{C}}$ Asset Index constructed with Principal Component Analysis, coded as $0=$ low household asset index, $1=$ high household asset index. 
the prevalence of high informal payments and increased need for health service utilization among younger women and their children [30]. With the meagre resources and a higher prevalence of disability, these women are at great risk of being confronted with the financial burden of OOP health expenditures. Many people rely on the services of traditional healers and face increased out-of-pocket health expenditure in Africa [22,31]. Our findings show that OOP costs for traditional healers are high among the adult participants. Culturally ingrained beliefs for various illnesses and inconsistencies in health service access urge them to seek the traditional healers with high OOP expenses [32]. Akin to earlier studies, obesity [33] and disability $[34,35]$ were also associated with higher OOP health expenditures in our study population. Disabilities during youth may be attributable to poor health status, related poor nutrition, living conditions and a high incidence of infectious diseases. Disabilities due to physical, functional, and psychiatric morbidities can affect the nature of health service utilization and demand high OOP health expenses among older people. A higher prevalence of disabilities among elderly are known to be associated with increased OOP health expenditure in LMICs [36]. Economic disadvantages related to the older peoples' disabilities can exacerbate their untreated medical illness, increase dependency and restrict their access to health services. Due to the absence of social security systems, the older people either suffer financial burden through OOP payments or remain disabled without seeking health care.

\section{Economic inequality and OOP health expenditure}

The socioeconomic status of both adult and older participants was inversely associated with OOP health expenditures in our study. African studies $[37,38]$ have consistently reported the differences in health care utilization and expenditure in terms of socioeconomic status. A study from Tanzania [39] also found that, occurrence of higher health care seeking and subsequent expenditure among the people with a higher socioeconomic status. OOP health expenditures remain an obstacle for health service utilization, and consistently increase the burden of diseases among people with poor literacy and low income laborers compared to the more affluent. Economic deprivation worsens the health status of these individuals and leads to decreased labor productivity [19]. The vicious cycle of further economic loss and increased vulnerability to illnesses predisposes to catastrophic health expenditures [40].

\section{Resources and need for OOP health expenditure}

OOP expenditure depends on the resources and healthcare needs of an individual. These resources and needs have a complex bidirectional interaction. The rich have better living conditions and better health, thereby reducing their needs for OOP health expenditure. However, they are endowed with better economic resources, education, enhanced awareness towards the need for health care and the thresholds at which they access that service are correspondingly lower. On the contrary, the poor and those with low literacy are less likely to use health services [16], especially preventive services, leading to worse health outcomes and subsequently increased need for OOP expenditures [40]. The need for OOP health expenditure that arises out of poor health determine the link between the economic inequality and inequities in the delivery of health care to people in LMICs. Gender inequality and unbalanced access to education additionally contribute and sustain healthcare inequities. Affordability remains a stronger determinant for OOP health expenditure than the valid need for essential health services.

\section{Catastrophic health expenditure}

Tanzanian households had a higher prevalence (18\%) of catastrophic health expenditure at the $40 \%$ threshold, compared to the observed prevalence in Burkina Faso (10.8\%) [7] and a lower prevalence than in Nigeria (27\%) [41]. Our results show that a low socioeconomic status of the household increased the probability for catastrophic expenses. The association between domestic violence against women and high health expenditures are well documented [42]. Women's welfare is vital to the household and injustice against them will affect their income contribution, health and well-being. Our finding chronic disease morbidity as an important determinant of catastrophic health expenditure has also been reported elsewhere [7]. The increased prevalence of chronic diseases in LMICs demands cost-effective control programs similar to infectious disease control programs to reduce the risk of catastrophic household health expenditure.

\section{Recommendations}

Our study highlighted the various determinants, potentially responsible for high OOP health expenditures among the adult and older population in Tanzania. To ensure equitable health care delivery for all, OOP health expenditure should be minimized. Hence, to reduce the financial barrier and improve the accessibility to health services the following are suggested,

1. Policies to reduce OOP expenditure should extend beyond curative medical attitudes, to include preventive social welfare aspects [43].

2. Cost efficient measures focused on the vulnerable sections of the community are essential for equitable health services. Regulation of user-fees [44], cross-subsidization strategies and provision of quality medical service [45] through low operating costs for women, the physically disabled and for 
the elderly may ease the burden of high OOP health expenditure.

3. Community financing through prepayment schemes has demonstrated some potential for provision of financial protection to all sectors of the population [46]. However, it has been difficult to operate these schemes due to low enrolment rates and drop-outs [47]. The evaluations of strategies for scaling up are required to increase enrolment and contribute to achievement of universal coverage.

4. Traditional healers are easily available in the rural communities. Suitable training of them could influence the health care system to prevent illness, promote health and refer the sick for specialized care $[48,49]$, which in turn would reduce the disease and financial burden. Although the adverse events are widely debated, studies argue the need for the integration of traditional healers into the health system [50].

5. Women's health is an integral epitome of a nation's wealth. Interventions such as provision of secondary education [51], improving the financial status of the labor division can eliminate economic barriers and enable them to control household funds. The overt financial burden faced by women due to reproductive care, childcare, along with poor incomes from manual labor can be avoided. The provision of gender sensitive health systems and entitlement to waivers can help the older women who abstain from seeking health services in spite of their significant health needs.

\section{Conclusion}

Our study shows that the adult and older participants differ in health care demands and health service expenditures. Different factors such as economic inequality, disparities in gender and prevalence of disabilities influence the OOP health expenditures in Tanzania. Public health policies that focus on social welfare programs to make the social security systems accessible for low socioeconomic groups are essential for the establishment of equitable health services. Health care policies should consider issues such as accessibility and affordability for health services among the productive adult and vulnerable older population.

\section{Competing interest}

All authors declare that they have no competing interests.

\section{Authors' contributions}

$E M B, U E, A R$ were involved in the study design. EMB developed the research question, performed the statistical analyses and drafted the manuscript. AR contributed to the data analysis and manuscript revisions. UE supervised the study design, interpretation of results and manuscript revisions. All authors read and approved the final manuscript.

\section{Acknowledgements}

We attribute this work to the Department of Public Health, Aarhus University, Denmark. We thank Associate Professor Jørn Atterman, Aarhus University, Denmark for providing statistical guidance. We also thank Ms. Janet Mikkelsen, Aarhus University, Denmark for reviewing the language of our manuscript.

Received: 29 October 2013 Accepted: 24 February 2014

Published: 5 March 2014

\section{References}

1. Pablo G, George S: Health Financing Revisited: A Practioner's Guide. Washington: World Bank; 2005.

2. Musgrove $P$, Zeramdini R, Carrin G: Basic patterns in national health expenditure. Bull World Health Organ 2002, 80(2):134-142.

3. You X, Kobayashi Y: Determinants of out-of-pocket health expenditure in China: analysis using China health and nutrition survey data. Appl Health Econ Health Policy 2011, 9(1):39-49.

4. Makinen M, Waters H, Rauch M, Almagambetova N, Bitran R, Gilson L, McIntyre D, Pannarunothai S, Prieto AL, Ubilla G, Ram S: Inequalities in health care use and expenditures: empirical data from eight developing countries and countries in transition. Bull World Health Organ 2000, 78(1):55-65.

5. Osmani S, Sen A: The hidden penalties of gender inequality: fetal origins of ill-health. Econ Hum Biol 2003, 1(1):105-121.

6. Boutayeb A, Helmert U: Social inequalities, regional disparities and health inequity in North African countries. Int J Equity Health 2011, 10:23.

7. Su TT, Kouyate B, Flessa S: Catastrophic household expenditure for health care in a low-income society: a study from Nouna District, Burkina Faso. Bull World Health Organ 2006, 84(1):21-27.

8. Onoka CA, Onwujekwe OE, Hanson K, Uzochukwu BS: Examining catastrophic health expenditures at variable thresholds using household consumption expenditure diaries. Trop Med Int Health 2011, 16(10):1334-1341.

9. United Nations: World Population Prospects: The 2012 Revision. New York: Population Division of the Department of Economic and Social Affairs; 2013.

10. World Health Organization: World Health Statistics. Geneva: WHO; 2013.

11. Ministry of Health: Health Sector Public Expenditure Review (2009/10). United Republic of Tanzania: Ministry of Health and Social welfare; 2011.

12. World Health Organization: Making Health Financing Work for Poor People in Tanzania: A Health Financing Policy Note. Geneva: WHO; 2011.

13. Mtei G, Borghi J: An Assessment of Health Care Financing Progressivity in Tanzania. Dar es Salaam: Ifakara Health Institute; 2010

14. Kayombo EJ, Uiso FC, Mahunnah RL: Experience on healthcare utilization in seven administrative regions of Tanzania. J Ethnobiol Ethnomed 2012, 8:5

15. Luong DH, Tang S, Zhang T, Whitehead M: Vietnam during economic transition: a tracer study of health service access and affordability. Int J Health Serv 2007, 37(3):573-588.

16. Albanese E, Liu Z, Acosta D, Guerra M, Huang Y, Jacob KS, JimenezVelazquez IZ, Llibre Rodriguez JJ, Salas A, Sosa AL, Uwakwe R, Williams JD, Borges G, Jotheeswaran AT, Klibanski MG, McCrone P, Ferri CP, Prince MJ: Equity in the delivery of community healthcare to older people: findings from 10/66 Dementia Research Group cross-sectional surveys in Latin America, China, India and Nigeria. BMC Health Serv Res 2011, 11(1):153.

17. Harris B, Goudge J, Ataguba JE, Mclntyre D, Nxumalo N, Jikwana S, Chersich M: Inequities in access to health care in South Africa. J Public Health Policy 2011, 32(Suppl 1):S102-123.

18. Aday LA, Andersen R: A framework for the study of access to medical care. Health Serv Res 1974, 9(3):208-220.

19. McIntyre D, Thiede M, Dahlgren G, Whitehead M: What are the economic consequences for households of illness and of paying for health care in low- and middle-income country contexts? Soc Sci Med 2006, 62(4):858-865.

20. Xu K, Evans DB, Kawabata K, Zeramdini R, Klavus J, Murray CJ: Household catastrophic health expenditure: a multicountry analysis. Lancet 2003, 362(9378):111-117.

21. Waweru LM, Kabiru EW, Mbithi JN, Some ES: Health status and health seeking behaviour of the elderly persons in Dagoretti division, Nairobi. East Afr Med J 2003, 80(2):63-67.

22. Uwakwe R, Ibeh CC, Modebe Al, Bo E, Ezeama N, Njelita I, Ferri CP, Prince MJ: The epidemiology of dependence in older people in Nigeria: 
prevalence, determinants, informal care, and health service utilization. A 10/66 dementia research group cross-sectional survey. J Am Geriatr Soc 2009, 57(9):1620-1627.

23. World Health Organization: Social Determinants Of Health. Geneva: WHO; 2011.

24. Sandefur J: Sample Design for the National Panel Survey. United Republic of Tanzania: National Bureau of Statistics; 2009.

25. Vyas S, Kumaranayake L: Constructing socio-economic status indices: how to use principal components analysis. Health Policy Plan 2006, 21(6):459-468.

26. Manning WG: The logged dependent variable, heteroscedasticity, and the retransformation problem. J Health Econ 1998, 17(3):283-295.

27. Basu A, Manning WG: Issues for the next generation of health care cost analyses. Med Care 2009, 47(7 Suppl 1):S109-114.

28. Kilian $\mathrm{R}$, Matschinger $\mathrm{H}$, Loeffler $\mathrm{W}$, Roick C, Angermeyer MC: A comparison of methods to handle skew distributed cost variables in the analysis of the resource consumption in schizophrenia treatment. J Ment Health Policy Econ 2002, 5(1):21-31.

29. Gregori D, Petrinco M, Bo S, Desideri A, Merletti F, Pagano E: Regression models for analyzing costs and their determinants in health care: an introductory review. Int I Qual Health C 2011, 23(3):331-341.

30. Maestad O, Mwisongo A: Informal payments and the quality of health care: mechanisms revealed by tanzanian health workers. Health Policy 2011, 99(2):107-115.

31. Nxumalo N, Alaba O, Harris B, Chersich M, Goudge J: Utilization of traditional healers in South Africa and costs to patients: findings from a national household survey. J Public Health Policy 2011, 32(Suppl 1):S124-136.

32. Verhagen LM, Kapinga R, van Rosmalen-Nooijens KA: Factors underlying diagnostic delay in tuberculosis patients in a rural area in Tanzania: a qualitative approach. Infection 2010, 38(6):433-446.

33. van Baal PH, Polder JJ, de Wit GA, Hoogenveen RT, Feenstra TL, Boshuizen $H C$, Engelfriet PM, Brouwer WB: Lifetime medical costs of obesity: prevention no cure for increasing health expenditure. PLoS Med 2008, $5(2): 229$.

34. Anderson WL, Armour BS, Finkelstein EA, Wiener JM: Estimates of statelevel health-care expenditures associated with disability. Public Health Rep 2010, 125(1):44-51.

35. Duba AS, Rajkumar AP, Prince M, Jacob KS: Determinants of disability among the elderly population in a rural south Indian community: the need to study local issues and contexts. Int Psychogeriatr 2012 24(2):333-341.

36. Sousa RM, Ferri CP, Acosta D, Albanese E, Guerra M, Huang Y, Jacob KS, Jotheeswaran AT, Rodriguez JJ, Pichardo GR, Rodriguez MC, Salas A, Sosa AL, Williams J, Zuniga T, Prince M: Contribution of chronic diseases to disability in elderly people in countries with low and middle incomes: a 10/66 Dementia Research Group population-based survey. Lancet 2009, 374(9704):1821-1830.

37. McElroy B, Wiseman V, Matovu F, Mwengee W: Malaria prevention in north-eastern Tanzania: patterns of expenditure and determinants of demand at the household level. Malar J 2009, 8:95.

38. Jefferis JM, Bowman RJ, Hassan HG, Hall AB, Lewallen S: Use of cataract services in eastern Africa-a study from Tanzania. Ophthalmic Epidemiol 2008, 15(1):62-65.

39. Schellenberg JA, Victora CG, Mushi A, de Savigny D, Schellenberg D, Mshinda $\mathrm{H}$, Bryce J: Inequities among the very poor: health care for children in rural southern Tanzania. Lancet 2003, 361(9357):561-566.

40. Van Doorslaer E, O'Donnell O, Rannan-Eliya RP, Somanathan A, Adhikari SR, Garg CC, Harbianto D, Herrin AN, Huq MN, Ibragimova S, Karan A, Lee TJ, Leung GM, Lu JF, Ng CW, Pande BR, Racelis R, Tao S, Tin K, Tisayaticom K, Trisnantoro L, Vasavid C, Zhao Y: Catastrophic payments for health care in Asia. Health Econ 2007, 16(11):1159-1184.

41. Onwujekwe O, Hanson K, Uzochukwu B: Examining inequities in incidence of catastrophic health expenditures on different healthcare services and health facilities in Nigeria. PLoS One 2012, 7(7):e40811.

42. Coker AL, Reeder CE, Fadden MK, Smith PH: Physical partner violence and medicaid utilization and expenditures. Public Health Rep 2004, 119(6):557-567.

43. Jacob KS: Public health in India and the developing world: beyond medicine and primary healthcare. J Epidemiol Community Health 2007, 61(7):562-563.

44. Haddad S, Nougtara A, Fournier P: Learning from health system reforms: lessons from Burkina Faso. Trop Med Int Health 2006, 11(12):1889-1897.
45. Bhattacharyya O, Khor S, McGahan A, Dunne D, Daar AS, Singer PA: Innovative health service delivery models in low and middle income countries - what can we learn from the private sector? Health Res Policy Syst 2010, 8:24.

46. Jütting JP, Msuya JM, Asfaw A: Impacts of Community Health Insurance Schemes on Health Care Provision in Rural Tanzania. University of Bonn: Center for Development Research; 2004.

47. Mtei G, Mulligan JA: Community Health Funds in Tanzania: A literature review. Dar es Salaam: Ifakara Health Institute; 2007.

48. Peltzer K, Mngqundaniso N, Petros G: A controlled study of an HIV/AIDS/ STI/TB intervention with traditional healers in KwaZulu-Natal, South Africa. AIDS Behav 2006, 10(6):683-690.

49. Mbeh GN, Edwards R, Ngufor G, Assah F, Fezeu L, Mbanya JC: Traditional healers and diabetes: results from a pilot project to train traditional healers to provide health education and appropriate health care practices for diabetes patients in Cameroon. Glob Health Promot 2010, 17(2 Suppl):17-26.

50. Freeman M, Motsei M: Planning health care in South Africa-is there a role for traditional healers? Soc Sci Med 1992, 34(11):1183-1190.

51. Sen G, Östlin P, George A: Unequal, Unfair, Ineffective And Inefficient Gender Inequity In Health: Why It Exists And How We Can Change It. Sweden: Karolinska institutet; 2007.

doi:10.1186/1472-698X-14-5

Cite this article as: Brinda et al:: Correlates of out-of-pocket and catastrophic health expenditures in Tanzania: results from a national household survey. BMC International Health and Human Rights 2014 14:5.

\section{Submit your next manuscript to BioMed Central and take full advantage of:}

- Convenient online submission

- Thorough peer review

- No space constraints or color figure charges

- Immediate publication on acceptance

- Inclusion in PubMed, CAS, Scopus and Google Scholar

- Research which is freely available for redistribution

Submit your manuscript at www.biomedcentral.com/submit
C) Biomed Central 